\title{
Off-design flow analysis of low-pressure steam turbines
}

\author{
M Petrovic ${ }^{1}$ and $\mathbf{W}$ Riess $^{2}$ \\ ${ }^{1}$ Department of Mechanical Engineering, University of Belgrade, Yugoslavia \\ ${ }^{2}$ Institute for Turbomachinery, University of Hannover, Germany
}

\begin{abstract}
In this paper, a method for flow calculation in large steam turbines is presented. The method is based on the through-flow theory and the finite element procedure. It includes some extensions and improvements in the form of a new combination of loss correlation, radial distribution of losses and spanwise mixing, a new procedure for density calculation and an extension to encompass reverse meridional flow. The method is applied to the LP (low-pressure) part of a $165 \mathrm{MW}$ steam turbine for which the flow field and performance over a wide range of mass flow and input pressure are calculated. The flow at far off-design loads, at which flow reversal behind the last stage occurs, and the last stage changes to ventilation are especially analysed. The comparison of numerical results with experimental data shows good correspondence.
\end{abstract}

Keywords: steam turbine, flow analysis, performance prediction, off-design operation, flow separation, reversal, loss model

\section{NOTATION}

b

$c$

$d$

$h$

$H$

$I$

$\dot{m}$

$p$

$p^{0}$

$\begin{array}{ll}\text { Subscripts } \\ \mathrm{Cl} & \text { clearance } \\ \mathrm{i} & \text { internal } \\ \text { in } & \text { inlet } \\ \text { out } & \text { outlet } \\ r & \text { radial component } \\ \mathrm{s} & \text { isentropic } \\ \mathrm{SW} & \text { secondary and end wall } \\ \mathrm{ts} & \text { total to static } \\ \mathrm{T} & \text { turbine } \\ u & \text { circumference component } \\ z & \text { axial component } \\ 0 & \text { design conditions }\end{array}$

\section{INTRODUCTION}

Off-design conditions occur on several occasions in steam turbines, e.g. at start-up, shutdown, at overnight part-load operation and, especially, in turbines with regulated steam extraction upstream of the LP (low-pressure) part, which may result in continuous LP operation at very low steam flow. In district heating plant turbines minimizing the mass flowrate through the LP part is attempted, because of the increasing heat needs at low atmospheric temperature. The change in the volume flow alters the velocity diagram for turbine stages and, consequently, it alters the efficiency and the performance of the turbine. A considerable flow departure from design conditions causes an increase in the cascade incidence angles and the profile losses and a decrease in the stage capability to generate mechanical 
energy. At very low flow conditions, a part of blading starts to work with energy consumption, i.e. rotating blades transmit energy into the flow by local ventilation. At far offdesign operation, flow separation and reversal occur in the hub region behind the last rotating blade row. The flow analysis and the behaviour prediction within a broad offdesign operation range is therefore very important, not only for an improvement in performance but also for an increase in reliability of steam turbines.

Although the through-flow methods are widely used in turbomachinery design, their application for off-design calculations in steam turbines is still connected with considerable uncertainty. The known codes based on classical through-flow theory are usually unable to treat low loads with ventilation and local meridional reverse flow.

The purpose of the work presented here is to develop a computing system for quick and accurate performance prediction and flow analysis of multistage gas and steam turbines over a wide range of speeds and loads. The method is based on a well-known through-flow theory and finite element solution procedure, but it also includes new details in a form of a new combination of loss and deviation correlation and extension to encompass reverse meridional flow. The results of extensive flow calculations for the LP part of a large steam turbine will be also presented herein.

\section{CALCULATION METHOD}

In a previous paper (1) the developed method was presented. Validation of the model and the computer program was performed by an extensive comparison of the numerical results with experimental data for a single-stage air turbine. The overall performance of the turbine could be well predicted in an operation range of mass flowrate: $0.2<\dot{m} / \dot{m}_{0} \leqslant 1.0$. Ventilation operation of the turbine with $\eta_{\mathrm{iT}}<0.0$ and $\boldsymbol{\Pi}=$ $p_{\text {in }}^{0} / p_{\text {out }}^{0} \approx 1.0$ was also analysed. Local flow separation and reversal behind the rotating blade row, which had been detected experimentally at low loads, were numerically confirmed. Agreement between the predicted size of the reverse flow region and experimental data was good. The method with extensions for calculations in steam turbines will be described briefly herein.

The method was developed on the basis of classical through-flow theory primarily using the analysis by Hirsch and Deconinck (2) and Bosman and Marsh (3). The flow is assumed to be steady, adiabatic and axisymmetric. The thermal equilibrium wet steam flow is considered. The two-dimensional calculation is made within a meridional hub-to-shroud surface, at which the momentum equation is projected, with the introduction of body forces replacing the blades and friction force to consider flow losses.

The resulting momentum equation has the following form:

$$
\frac{\partial^{2} \psi}{\partial r^{2}}+\frac{\partial^{2} \psi}{\partial z^{2}}=\left\lceil\frac{2 \pi}{\dot{m}} q-\frac{\partial \psi}{\partial r} \frac{\partial}{\partial_{r}}\left(\frac{1}{\rho r b}\right)-\frac{\partial \psi}{\partial z} \frac{\partial}{\partial z}\left(\frac{1}{\rho r b}\right)\right\rceil(\rho r b)
$$

where $q$ is a function of the turbine geometry, velocities and fluid properties distribution $(\mathbf{1}, \mathbf{2})$. The stream function is defined by the following relations:

$$
\frac{\partial \psi}{\partial r}=\frac{2 \pi}{\dot{m}} \rho r b w_{z}, \quad \frac{\partial \psi}{\partial z}=-\frac{2 \pi}{\dot{m}} \rho r b w_{r}
$$

where $\dot{m}$ is the mass flowrate and $b$ is the tangential blockage factor $(b=1-d / t$, where $d$ is the tangential blade thickness and $t$ is the blade pitch).

The mass flow $\dot{m}$ is introduced in the stream function equations in order to achieve an easier definition of boundary conditions. Namely, the boundary conditions for turbines without extractions are defined with $\psi=0.0$ along the hub and $\psi=1.0$ along the shroud. Since $\dot{m}$ is included in equation (2), it remains constant during calculations for the whole turbine operating range: nominal and part loads. In the case of turbines with extraction, the value of the stream function in calculating points at the shroud downstream of extraction locations has to be simply reduced according to the extracted mass flowrate.

By solving the momentum equation (1) with the introduction of the continuity equation, the energy equation and the equation of state, the velocity vector and the thermodynamic state of working fluid are obtained. A loss model is applied to calculate entropy variation, while a deviation model is applied to determine the circumferential component of the flow velocity. The overall performance of the turbine and parameters of separate stages may be obtained from the calculated flow field.

\section{LOSS AND DEVIATION MODEL}

For a loss coefficient prediction and an entropy increase calculation at the design operating point, the loss model of Traupel (4) was applied. Loss coefficients by Traupel are given as functions of geometric and flow parameters in the form of several diagrams. For present calculations these functions were approximated with polynomials (5). For large incidence angles the correlation of Zehner (10) was applied.

Experiments show that flow losses are greater in end-wall regions of blade rows. In order to take this fact into account, a new model for radial loss distribution was applied. The model is based on the extensive experimental investigation by Groschup (6) and further developed at the Institute for Turbomachinery by Petrovic and Riess (1). The model assumes that secondary, end-wall and clearance losses are concentrated at the hub and shroud region of blade rows, whose width is determined using Traupel's correlation (4). To distribute secondary, end-wall and clearance loss coefficients within this range the function $\mathrm{e}^{x^{2}}$ was selected. The parameters of the function are estimated according to the experimental data.

To avoid unrealistic accumulations of entropy increases in end-wall regions, a spanwise mixing model was developed 


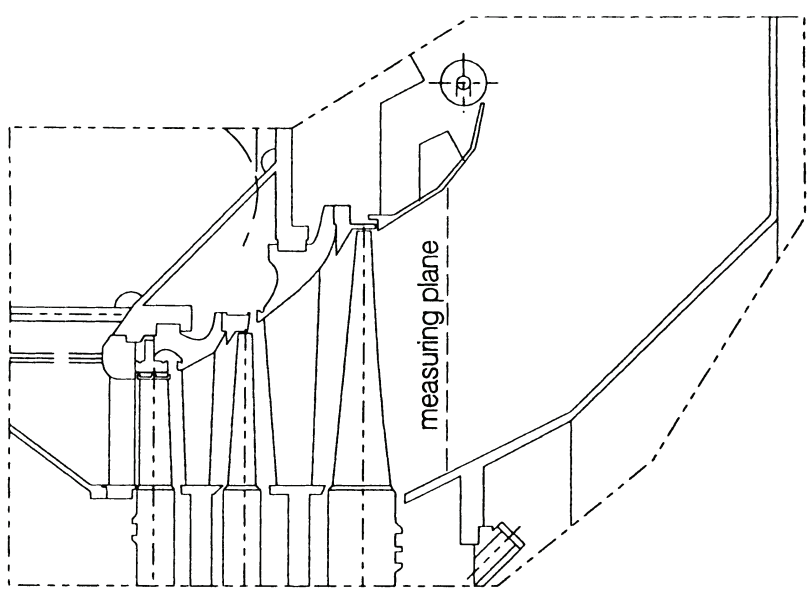

Fig. 1 Low-pressure part of the $165 \mathrm{MW}$ steam turbine

and applied $(\mathbf{1}, \mathbf{5})$. The model realizes the mathematical redistribution of entropy $s$, total enthalpy $H$ and angular momentum $r c_{u}$ within axial gaps between the blade rows and outlet diffuser. It encloses the same integral values of $s, H$ and $r c_{u}$ along a span but with smaller radial gradients.

Finally, for cascade exit flow angle calculations, a new correlation in the form of a corrected sine rule $\left(\sin \beta_{2}=a / t\right.$, where $a$ is throat width and $t$ is blade pitch) is developed. The deviation of the exit flow angle is assumed to be proportional to the local value of the secondary, end-wall and clearance loss coefficients, $\zeta_{\mathrm{SW}}$ and $\zeta_{\mathrm{Cl}}$ :

$$
\beta_{2}=a \sin \left\lceil K_{\mathrm{a}} \frac{1}{\sqrt{ }\left(1+\zeta_{\mathrm{SW}}+\zeta_{\mathrm{Cl}}\right)} \frac{a}{t}\right\rceil+K_{\mathrm{y}}
$$

where $\beta_{2}$ is calculated in degrees. Factor $K_{\mathrm{y}}$ considers the additional flow deviation in the wet steam region:

$$
K_{\mathrm{y}}=20 y_{1}
$$

where $y_{1}$ is the wetness fraction at the cascade inlet and $K_{\mathrm{a}}$ is the correcting factor for supersonic flow (7):

$$
K_{\mathrm{a}}=\left\lceil\frac{2}{\kappa-1}\left(\frac{\kappa+1}{2}\right)^{(\kappa+1) /(\kappa-1)}\left(\varepsilon^{2 / \kappa}-\varepsilon^{(\kappa+1) / \kappa}\right)\right]^{1 / 2}
$$

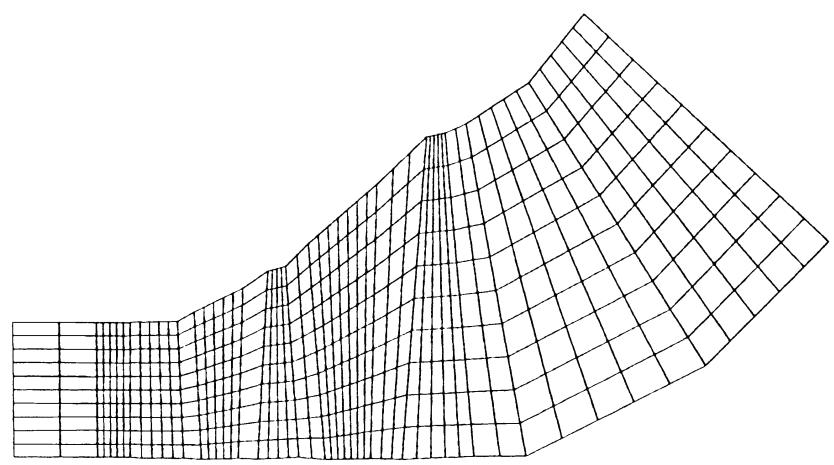

Fig. 2 Finite element distribution of the LP turbine A01997 (C) IMechE 1997 where $\varepsilon$ is the cascade pressure ratio, $\varepsilon=\left(p_{2} / p_{1}^{0}\right)$, with $p_{1}^{0}=$ $f\left(s_{1}, h_{1}+w_{1}^{2} / 2\right)$ for the rotor and $p_{1}^{0}=f\left(s_{1}, h_{1}+c_{1}^{2} / 2\right)$ for the stator $(1=$ cascade inlet, $2=$ cascade outlet $)$. For the subsonic flow $K_{\mathrm{a}}=1.0$.

\section{CALCULATION OF STEAM PROPERTIES}

Most methods for LP steam flow calculations approximate low-pressure dry steam and wet steam by a perfect gas using the corresponding simple equations for steam properties. In order to make the present procedure as accurate as possible, the steam is assumed to be a real gas. An equation for the free energy $f=f(\rho, T)(\mathbf{8})$ is applied. This makes a very accurate computation of steam properties possible. However, steam properties calculation using complicated analytical equations decelerates the procedure considerably. The most frequently used function, $\rho=\rho(h, s)$, does not exist as a direct function and $\rho$ has to be calculated using an iteration process, which significantly slows down the
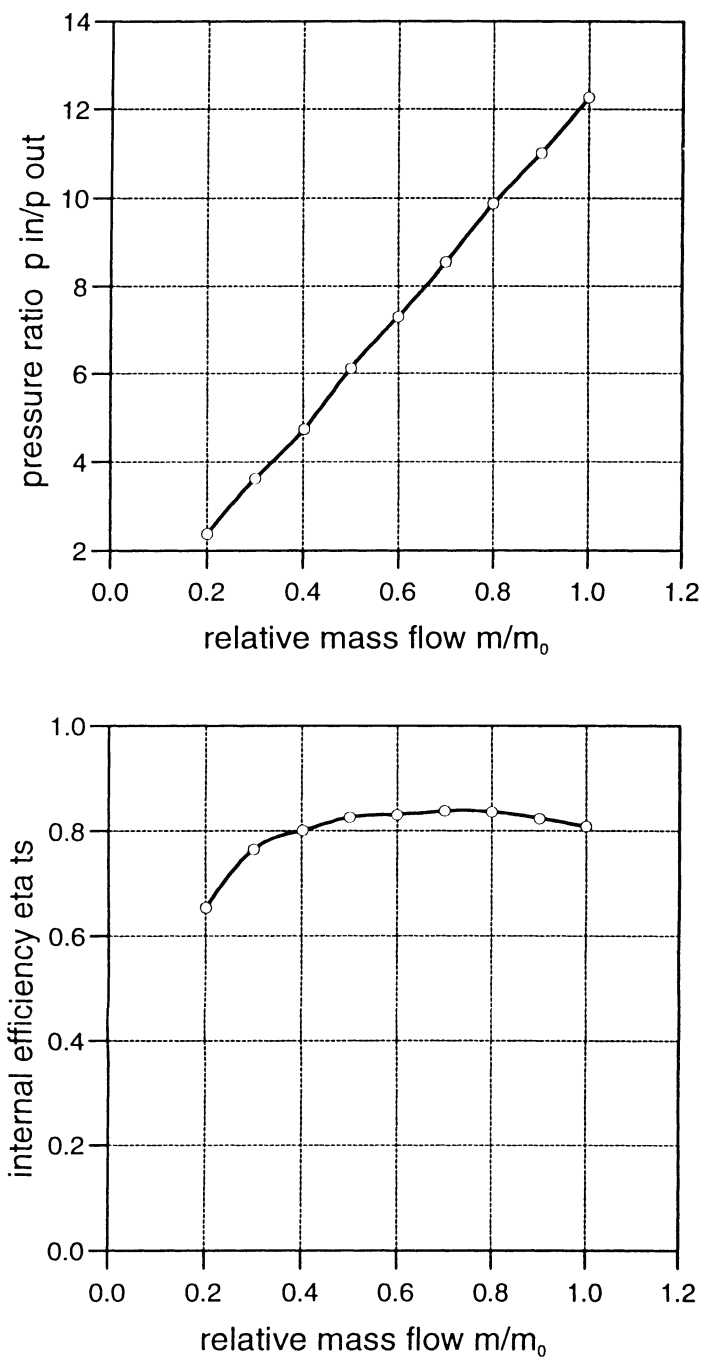

Fig. 3 LP steam turbine overall performance 


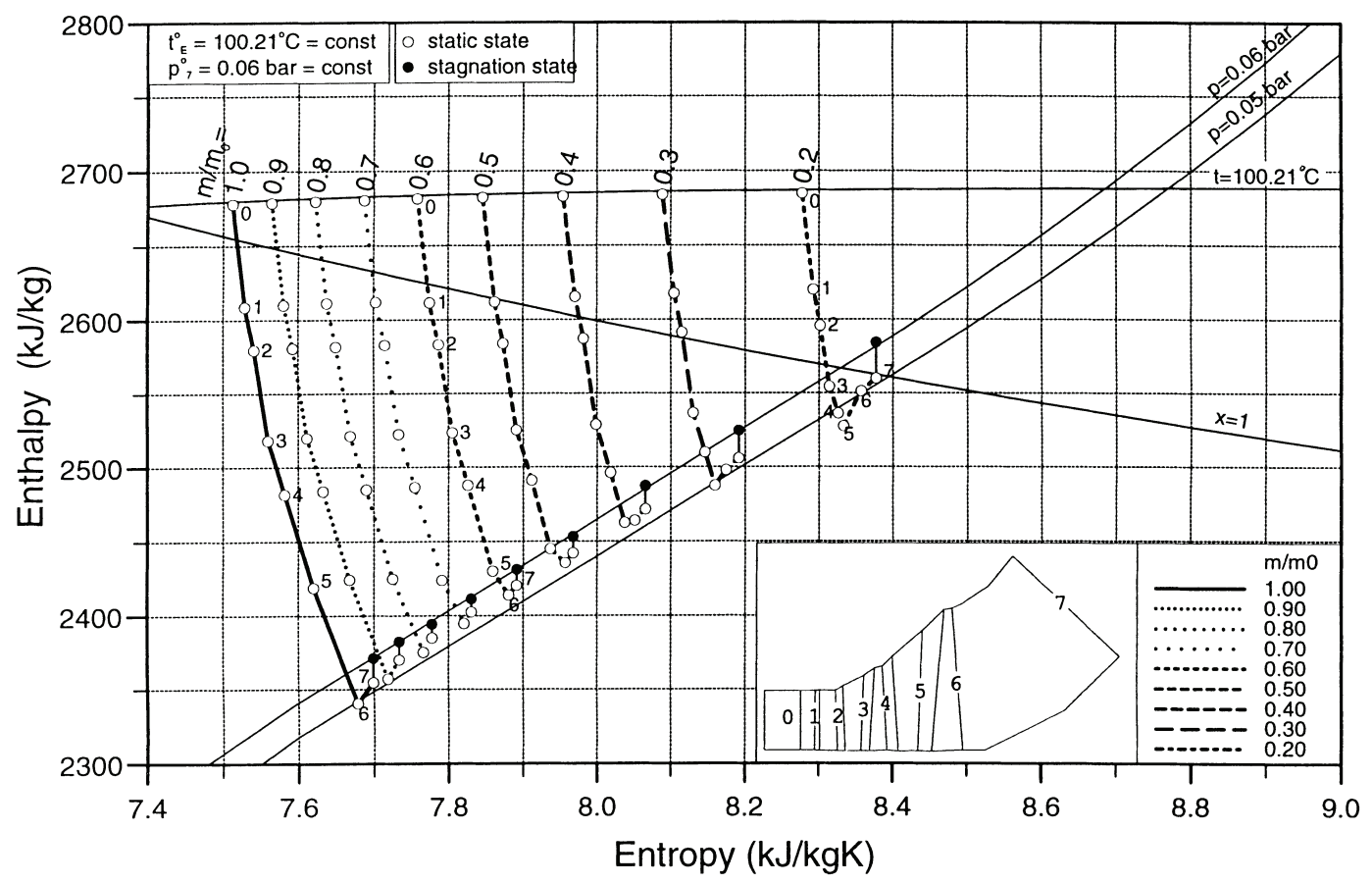

Fig. 4 Expansion in the LP steam turbine

method. In order to avoid this, the values of $\rho=\rho(h, s)$ were calculated for the whole turbine operating range during the preprocessing phase and stored in matrix form in the computer memory. Values of $h$ and $s$ were changed using a fine increment so that the density $\rho$ may be determined very accurately and quickly from these tables using a simple interpolation process. The calculation of other functions, which are more frequently used, were solved in the same way.

\section{DENSITY CALCULATION}

During the calculation of flow parameters at a point in the grid the values of $H, s, c_{\mathrm{u}}$ are found. The total enthalpy $H$ (i.e. the rothalpy $I$ within rotating blade rows) remains constant along a streamline. The entropy $s$ is obtained using the loss model, while the circumferential velocity component $c_{u}$ is determined using the deviation model. The density $\rho$ and meridional velocity components, $w_{z}$ and $w_{r}$, are unknown and need to be computed.

Since a real gas model is used, the procedure developed by Hirsch (2), where the correlations for a perfect gas were used, could not be applied. Therefore, a new similar procedure was developed.

For static enthalpy the following equation is valid:

$$
h=H-\frac{c^{2}}{2}
$$

Using the definition of the stream function [equation (2)], the velocity may be written as

$$
c^{2}=c_{z}^{2}+c_{r}^{2}+c_{u}^{2}=\frac{\dot{m}^{2}}{(2 \pi \rho r b)^{2}}\left[\left(\frac{\partial \psi}{\partial r}\right)^{2}+\left(\frac{\partial \psi}{\partial z}\right)^{2}\right]+c_{u}^{2}
$$

With

$$
\begin{aligned}
& A=\frac{1}{2} \frac{\dot{m}^{2}}{(2 \pi b r)^{2}}\left[\left(\frac{\partial \psi}{\partial r}\right)^{2}+\left(\frac{\partial \psi}{\partial z}\right)^{2}\right] \\
& B=\frac{c_{u}^{2}}{2}
\end{aligned}
$$

equation (6) takes following form:

$$
h=H-\frac{A}{\rho^{2}}-B
$$

Since function $\rho=f(h, s)$ is known and the values of parameters $A$ and $B$ may be estimated using the start distribution of the stream function, equation (9) becomes

$$
h=H-\frac{A}{[\rho(h, s)]^{2}}-B=f(h)
$$

Applying a simple iterative process to solve equation (10), 


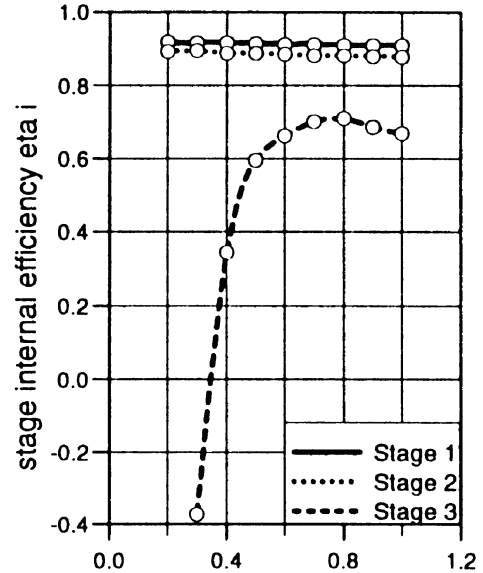

(a)

relative mass flow $\mathrm{m} / \mathrm{m}_{0}$

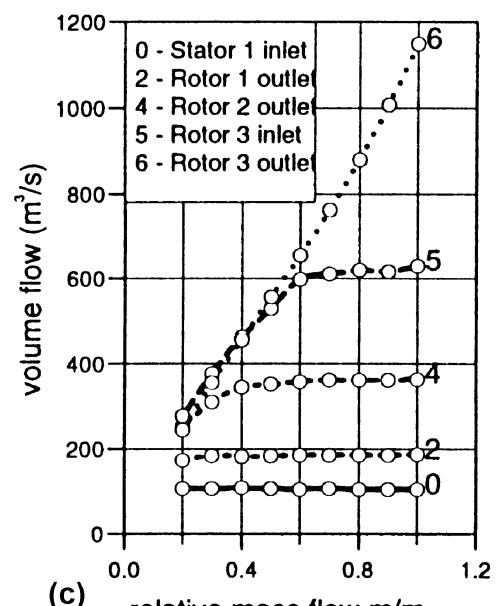

(c) relative mass flow $\mathrm{m} / \mathrm{m}_{0}$

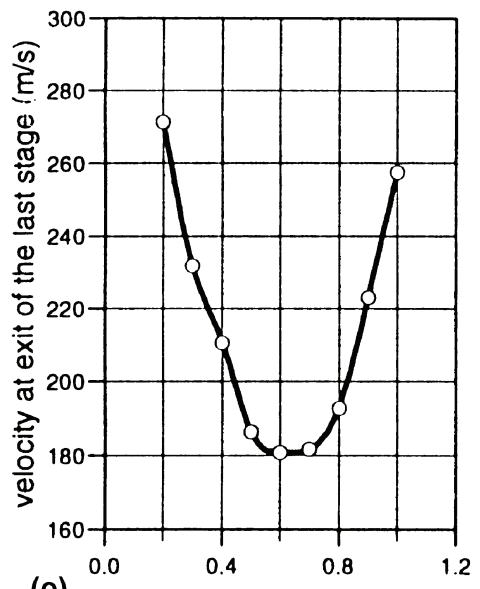

(e) relative mass flow $\mathrm{m} / \mathrm{m}$

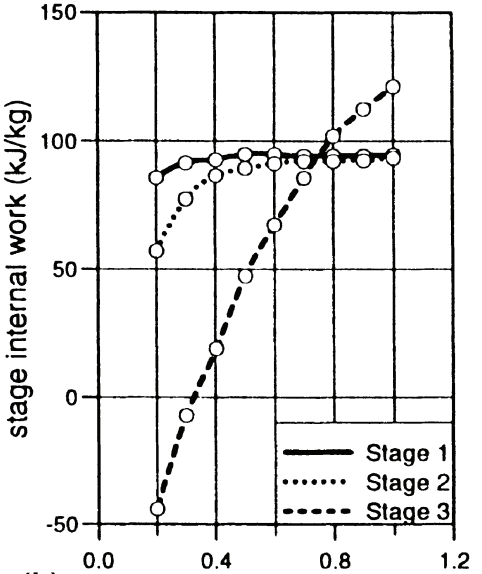

(b) relative mass flow $\mathrm{m} / \mathrm{m}$

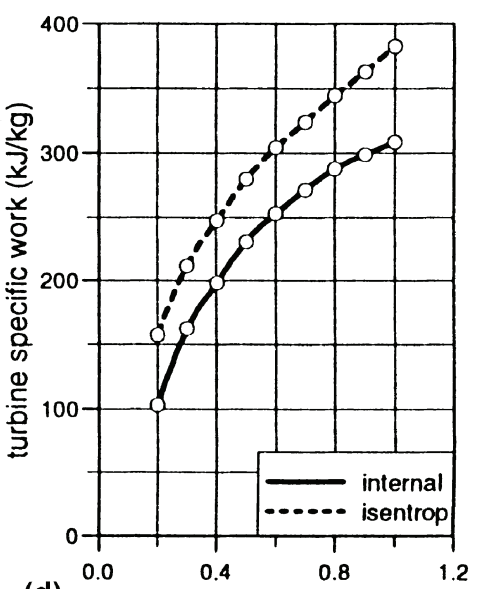

(d) relative mass flow $\mathrm{m} / \mathrm{m}_{0}$

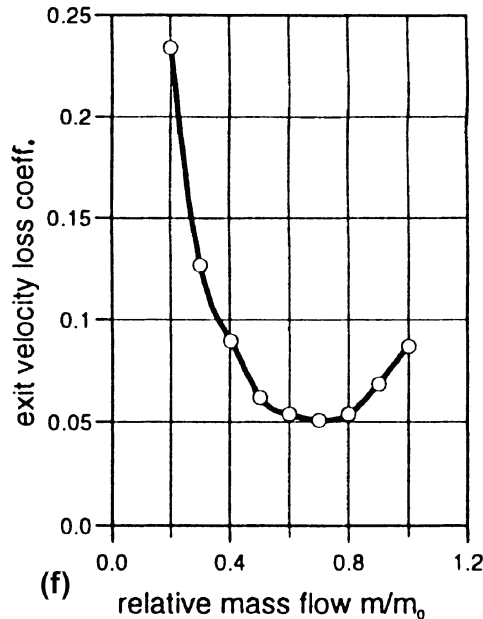

Fig. 5 Calculated variation of stage parameters of the LP turbine

the static enthalpy $h$ may be determined, where $h=H$ is used as the start value. The process converges quickly and only a few iteration steps are necessary. Since the entropy $s$ is known, the density $\rho$ is obtained using the function $\rho=\rho(h, s)$. The axial and radial velocity components, $w_{z}$ and $w_{r}$, are computed using the stream function definition [equation (2)].

\section{SOLUTION METHOD}

The governing through-flow equation (1) is a second-order, quasi-linear partial differential equation. It is elliptic for subsonic meridional flow and may be solved iteratively using discretization on a fixed grid. Here the finite element method with eight-noded isoparametric, quadrilateral 

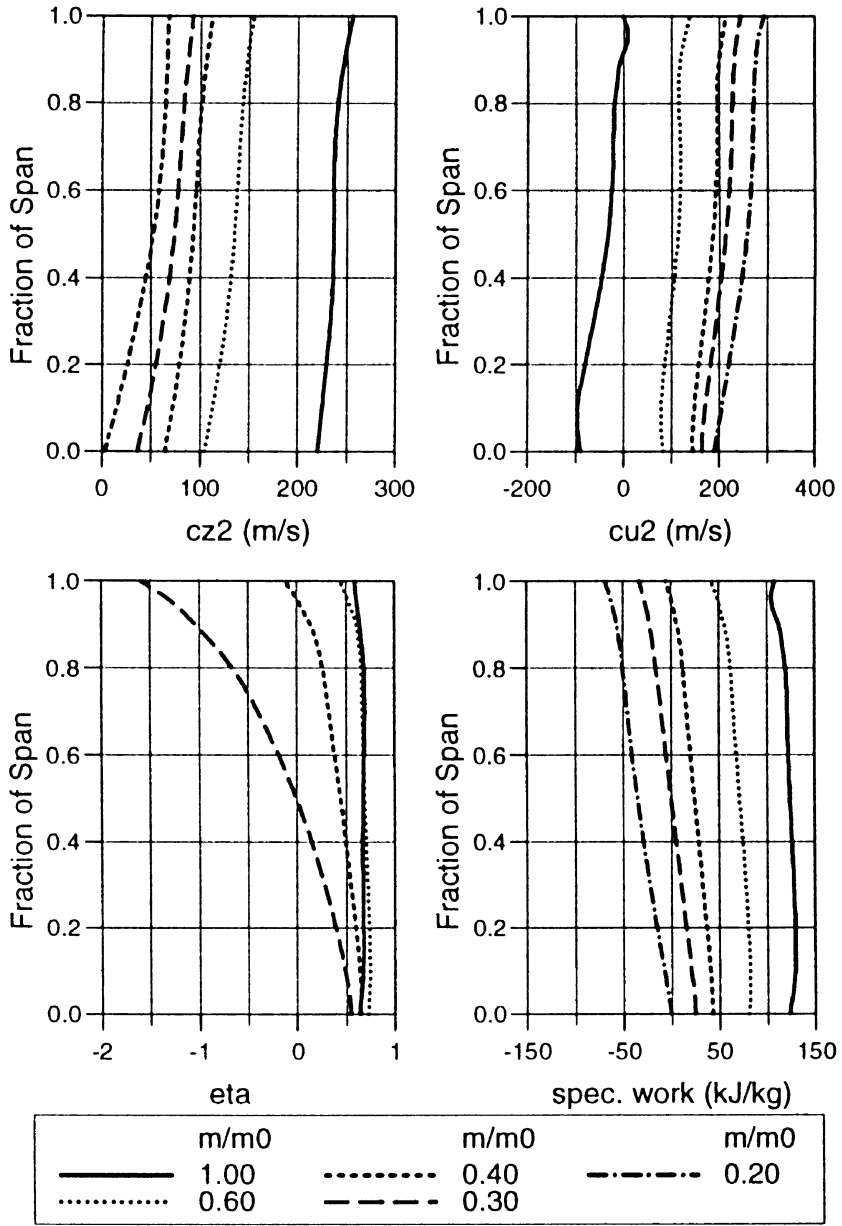

Fig. 6 Calculated radial profiles of efficiency, specific work and exit velocities of the last stage

elements and biquadratic interpolation functions was used. The Galerkin procedure using a weighted residual was applied to form the finite element equations, while the frontal solving method was used to solve the resulting system of linear equations. The computer program was written in FORTRAN and the IBM RISC 6000 workstation was used for calculations.

\section{ANALYSIS OF THREE-STAGE LP STEAM TURBINE}

Two LP steam turbines, for which measurements of the flow distribution are available, were analysed to ensure reliability of the method and to determine its limitations. The calculation reported here is of flow in the low-pressure part of a $165 \mathrm{MW}$ steam turbine designed to operate at $3000 \mathrm{r} / \mathrm{min}$. The turbine was produced by MAN Energie-Nürnberg and installed in a district heating plant in Hamburg. The turbine geometry is shown in Fig. 1. The blade length, the geometry of the last stage and the exhaust diffuser are typical of modern LP cylinders. The steam extraction for district heating is located upstream from the LP part and regulated by a throttle valve. The mass flow varies from a maximum value in summer to a minimum value at low atmospheric temperature during winter. Therefore, the investigation of the turbine part-load flow and behaviour is important. Extensive aerodynamic measurements of the flow field behind the last stage over a wide range of loads were performed by the Institute for Turbomachinery (9). A five-hole probe was applied to acquire data about the three-dimensional flow. The measuring plane is also shown in Fig. 1.

The calculated domain with element distribution is shown in Fig. 2. The grid refinement study was performed to make the computing time shorter. It was concluded that the use of 10 elements in the radial direction gives very good results. In the axial direction three elements per blade row were used. In order to obtain more information about flow, for the last stage of blade rows four elements in the axial direction were applied.

Flow calculations have been performed for the nominal load and several part loads. At the design operation point, steam conditions at the LP turbine inlet were $t_{\text {in }}^{0}=100.21^{\circ} \mathrm{C}$, $p_{\text {in }}^{0}=0.735$ bar and pressure at the trailing edge of the last turbine stage $p_{6}=0.05$ bar. Calculations were made assuming that at all part loads the inlet temperature $\left(t_{\text {in }}^{0}=\right.$ $\left.100.21^{\circ} \mathrm{C}\right)$ and total pressure at the diffuser outlet $\left(p_{7}^{0}=\right.$ 0.06 bar) remained constant. The mass flowrate was varied from $\dot{m} / \dot{m}_{0}=1.0$ to $\dot{m} / \dot{m}_{0}=0.2\left(\dot{m}_{0}\right.$ is the design mass flow). The inlet pressure of every individual part load was obtained iteratively.

Diagrams showing the calculated turbine performance, pressure ratio and turbine efficiency as functions of mass flow are presented in Fig. 3. The pressure ratio is defined as the relation between total pressures at the turbine inlet and outlet, $\boldsymbol{\Lambda}=p_{\text {in }}^{0} / p_{\text {out }}^{0}$, and the efficiency is calculated with total enthalpy at the inlet and static enthalpy at the outlet. Figure 4 presents the $h-s$ diagram of the turbine expansion process for nominal load and several part loads. The expansion lines were created with the thermodynamic state of steam which was averaged over the mass flow. The variation of different stage parameters is shown in Fig. 5. The turbine performance was given as a function of the mass flowrate $\dot{m} / \dot{m}_{0}$ in order to make discussion of the results easier. It would have been more general if the pressure ratio $\boldsymbol{H}$ or the available isentropic turbine enthalpy difference had been used as the variable. Nevertheless, using the given diagrams it is possible to recalculate the turbine performance as a function of other variables.

Values of volume flow at the LP turbine inlet and in plane 2 behind the first stage remain practically constant (Fig. 5c) since with a reduction of the mass flow the inlet pressure decreases similarly at a constant inlet temperature. The flow field and velocity triangles remain approximately unchanged over the whole calculated operating range and, consequently, the specific stage work and stage efficiency remain unchanged as well (Figs 5a, 5b and 4). 


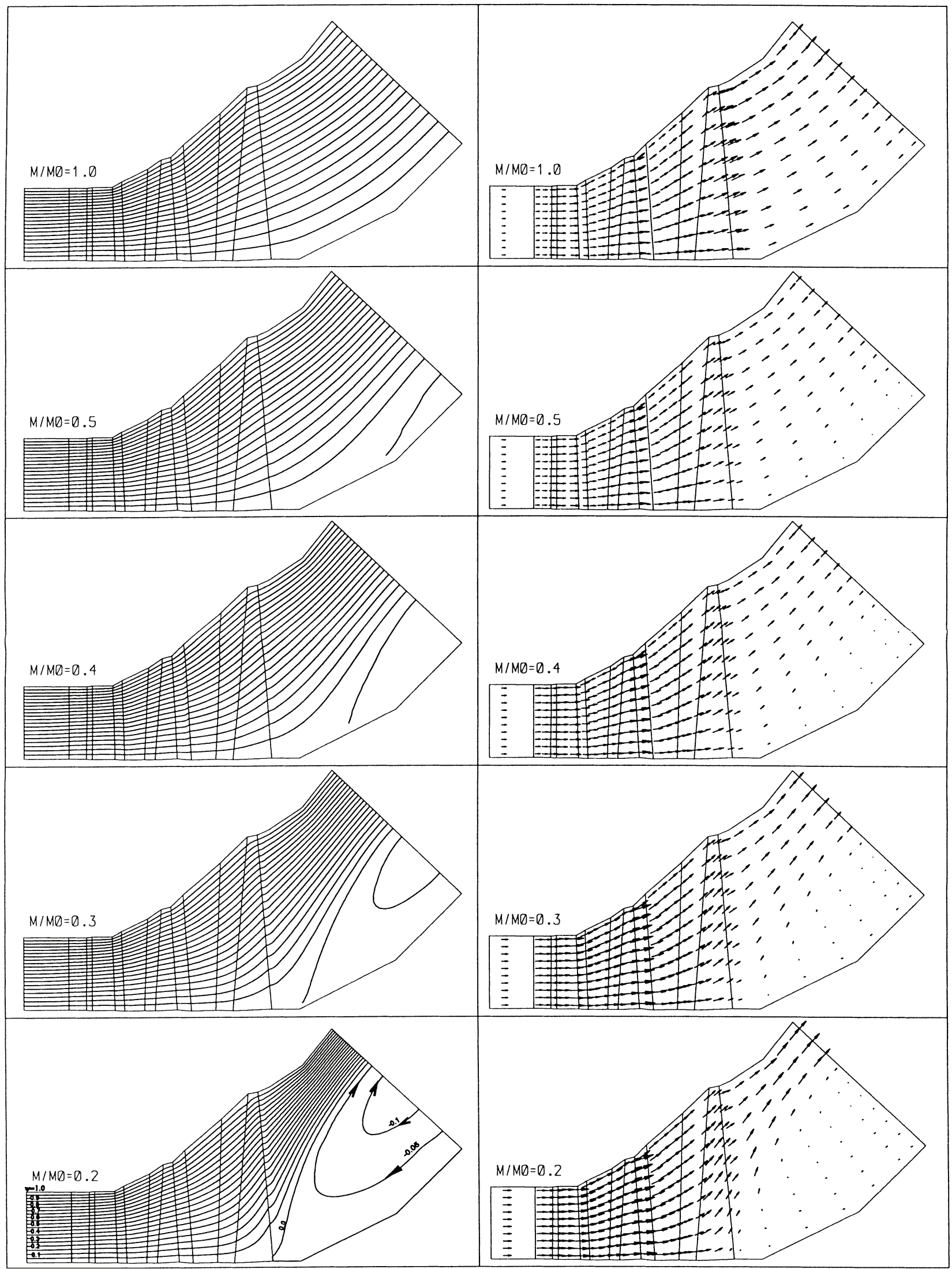

Fig. 7 Streamlines and velocity vectors in the meridional surface of the LP steam turbine at design load and several part loads. The increment between streamlines is $\Delta \phi=0.05$. The meridional velocity vectors are scaled at a maximum value for every calculation case 

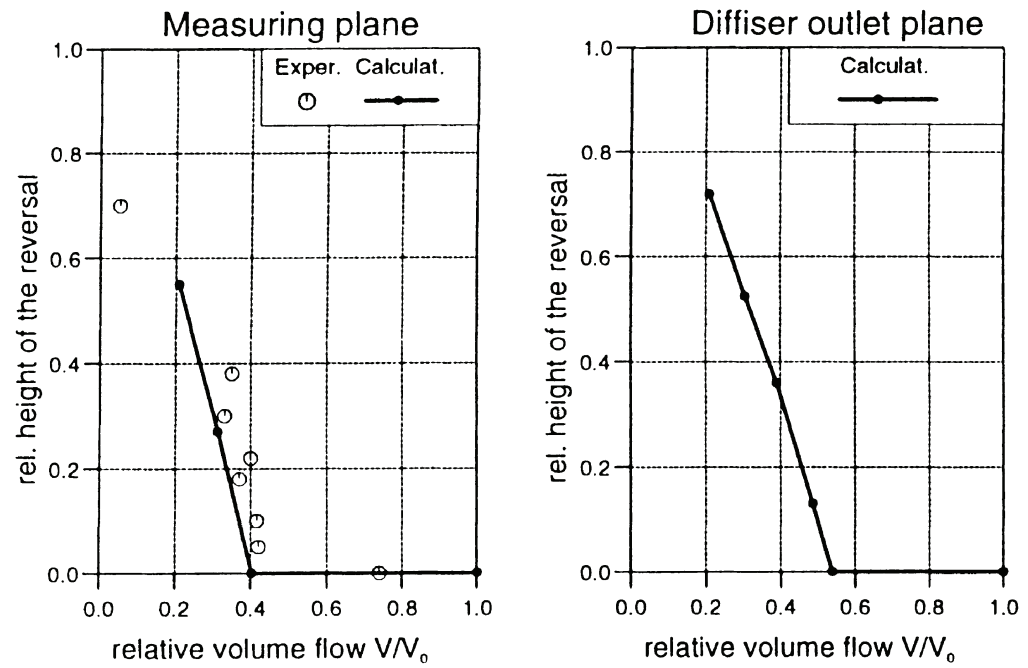

Fig. 8 Height of the reverse-flow region at the measuring plane and at the outlet plane

Volume flow in the second stage decreases very slightly by reducing mass flow until $\dot{m} / \dot{m}_{0}=0.4$ but after that it decreases somewhat quicker (Fig. $5 \mathrm{c}$ ). Specific stage work and the enthalpy difference of the second stage decrease more intensively only at $\dot{m} / \dot{m}_{0}<0.4$ (Figs 5 b and 4).

By reducing the mass flow from a nominal value $\dot{m}_{0}$ to $\dot{m}=0.2 \dot{m}_{0}$, the efficiency of the first and the second stages slightly increases (Fig. 5a). This happens due to the fact that the changes of volume flow and velocity triangles are minimal and the change of profile, secondary and clearance losses is negligible. On the other hand, the wetness fraction $y$ diminishes (Fig. 4), resulting in smaller total flow losses in the first two stages.

In the last stage, however, reduction of the mass flow causes the volume flow and stage work to decrease rapidly (Figs $5 \mathrm{~b}$ and $5 \mathrm{c}$ ). The efficiency of the last stage slightly increases by changing $\dot{m}$ from $\dot{m}=\dot{m}_{0}$ to $\dot{m}=0.7 \dot{m}_{0}$ due to a smaller wetness fraction in the flowing steam and a lower exit velocity. In the case of a further mass flow reduction $\left(\dot{m} / \dot{m}_{0}=0.7\right.$ goes to 0.2$)$, the efficiency of the last stage decreases very quickly since incidence angles and flow losses become larger and the available stage enthalpy difference becomes smaller.

The absolute velocity at the exit of the third stage (Fig. 4e) falls by changing $\dot{m} / \dot{m}_{0}$ from 1.0 to 0.7 and increases afterwards, because of intensive growth of the circumferential component at part loads (Fig. 6). This is caused by reduction of the axial velocity component at a smaller volume flow at part loads. The behaviour of the exit velocity loss coefficient $\zeta_{c_{2}}=c_{2}^{2} / \Delta h_{\mathrm{sT}}$ is similar (Fig. 5f): at low part loads $\zeta_{c_{2}}$ is large since $c_{2}$ is high and the isentropic enthalpy difference of the turbine $\Delta h_{\mathrm{sT}}$ becomes small (Fig. $5 \mathrm{~d}$ ).

At $\dot{m} / \dot{m}_{2} \approx 0.35$ the efficiency and the internal specific work of that third stage approach zero: $\eta_{i, 3}=0$ and $\Delta h_{\mathrm{i}, 3}=0$. The stage changes to ventilation operation, and at lower mass flowrates the last stage works with energy consumption. In Fig. 4 it can be seen how by reducing $\dot{m}$ the enthalpy difference of the last stage rotating blade row decreases extremely quickly. At $\dot{m} / \dot{m}_{0}=0.4$ there is no expansion in the last stage rotor. At $m / \dot{m}_{0}=0.3$ and $\mathrm{m} / \dot{m}_{0}=0.2$ the enthalpy at the exit of the last rotating blade row is higher than at the inlet- the streaming fluid is compressed there (Fig. 4).

Figure 6 shows radial profiles of axial and circumferential components of the absolute flow velocity at the exit of the last rotating blade row and radial profiles of efficiency and specific work of the last stage. It can be seen that already at $\dot{m} / \dot{m}_{0}=0.4$ the top part of the stage operates with negative work and efficiency. At $\dot{m} / \dot{m}_{0}=0.3$ work and efficiency of the last stage along the top part of the blade are negative (ventilation operation), while they are positive along the bottom part. At $\dot{m} / \dot{m}_{0}=0.2$ the whole last stage works with energy consumption.

Figure 7 shows the results of flow field calculations: streamlines and velocity vectors in the meridional surface for design operation and several part loads. The flow separation and flow reversal in the hub region behind the last rotating blade row were first detected at $\dot{m} / \dot{m}_{0}=0.5$. The region with reverse flow grows by reducing the mass flowrate. The meridional component of velocity in flow reversal is small, so that only a small fraction of the mass flow streams into this region: at $\dot{m} / \dot{m}_{0}=0.3$ the mass flowrate of the reverse flow amounts to approximately 8 per cent and at $\dot{m} / \dot{m}_{0}=0.2,13$ per cent of the mass flow is in the main stream. The results of calculations of the height of the reverse-flow region and a comparison of measuring data for the measuring plane are shown in Fig. 8. The operating point at which in the measuring plane the flow separation occurs $\left(\dot{m} / \dot{m}_{0} \approx 0.4\right)$ is well predicted, as is also the height of the reverse-flow region.

Figure 9 presents the calculated results of several flow parameters in the measuring plane and a comparison with experimental data produced by Schmidt et al. (9). Agreement throughout is good. More significant differences 

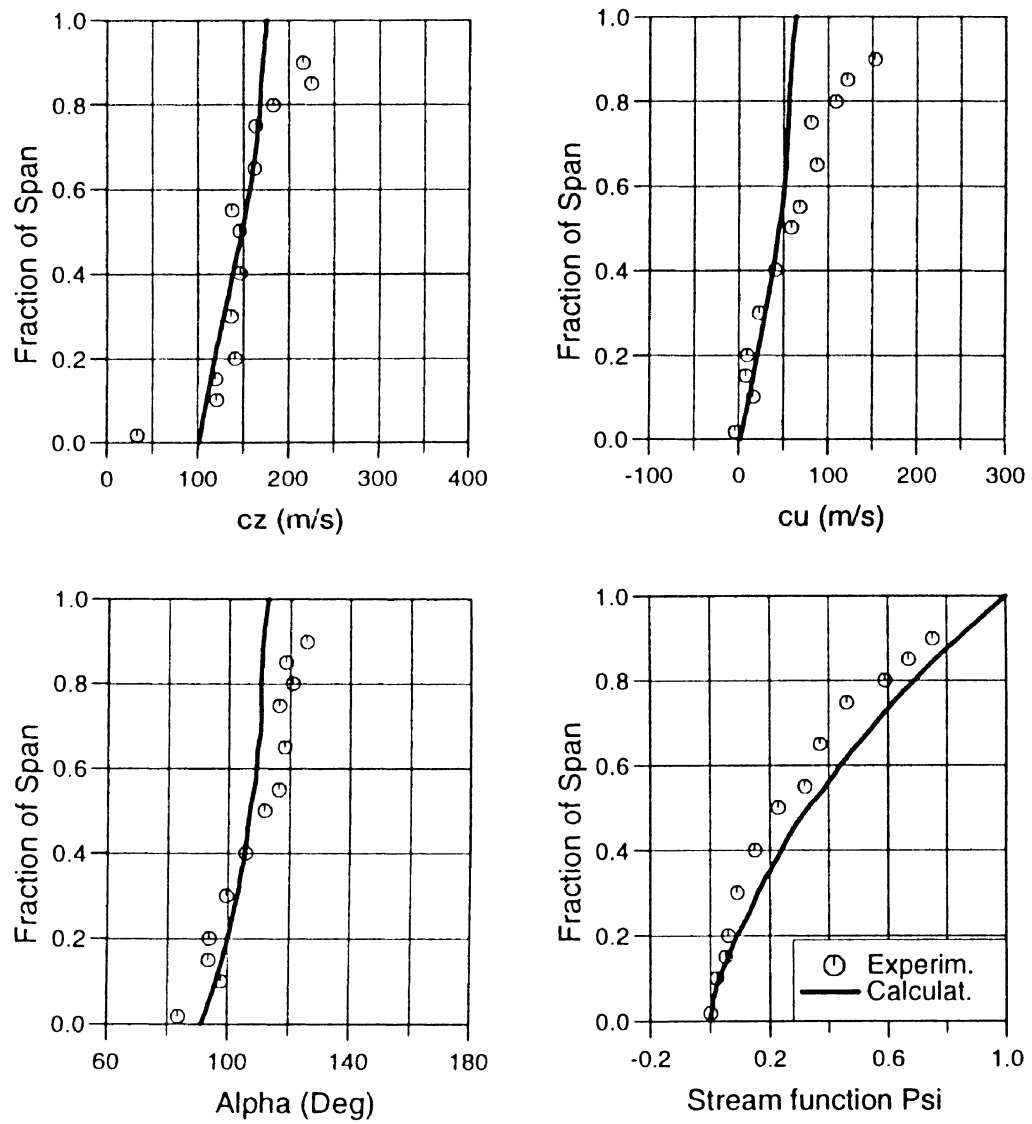

Fig. 9 Comparison of measured and calculated radial profiles of several operating parameters at the exit of the last stage at $\dot{V} / \dot{V}_{0}=0.74$

between simulation and experiment of the flow parameter appears in the top region. This could be explained by the strong influence of the secondary flow and clearance, although these effects are included in the calculations, and by the high concentration of the liquid phase in this region.

\section{CONCLUSION}

A method for through-flow calculations in axial flow turbines based on the finite element procedure is presented. The method is used to calculate the flow field and to predict the overall performance of the three-stage LP part of a $165 \mathrm{MW}$ steam turbine. The behaviour of the turbine over a wide operating range $\left(0.2<\dot{m} / \dot{m}_{0}<1.0\right)$ is analysed. The results show very little change in the flow field and performance of the first two stages throughout the analysed operating range. The behaviour changes in the last stage are significant. At $\dot{m}=0.4 \dot{m}_{0}$, the top part of the last stage starts to work with power consumption. At $\dot{m} \approx 0.35 \dot{m}_{0}$ the efficiency and the internal work of the last stage become zero so that the stage changes to a ventilation operation. A small separation and reversal flow in the hub region behind the last rotating blade row was first detected at $\dot{m} \approx 0.5 \dot{m}_{0}$. By further reduction of the mass flow the size of the flow reversal increased. Comparisons of numerical results and experimental data show good agreement.

\section{REFERENCES}

1 Petrovic, M. and Riess, W. Through-flow calculation in axial flow turbines at part load and low load. In First European Conference on Turbomachinery-Fluid Dynamic and Thermodynamic Aspects, Erlangen, 1995.

2 Hirsch, Ch. and Deconinck, H. Through flow models for turbomachines: stream surface and passage averaged representations. In Thermodynamics and Fluid Mechanics of Turbomachinery, Vol. 1 (Eds A. S. Ucer, P. Stow and Ch. Hirsch), 1985 (Martin Nijhoff Publishers, Dordrecht, The Netherlands).

3 Bosman, C. and Marsh, H. An improved method for calculation of the flow in turbo-machines, including a consistent loss model. J. Mech. Engng Sci., 1974, 16.

4 Traupel, W. Thermische Turbomaschinen, Vol. 1, 1988 (Springer-Verlag, Berlin).

5 Petrovic, M. Berechnung der Meridianströmung in mehrstufigen Axialturbinen bei Nennund Teillastbetrieb. Dissertation, University of Hanover, 1995; also VDI Fortschrittberichte, 7(280). 
6 Groschup, G. Strömungstechnische Untersuchung einer Turbinenstufe im Vergleich zum Verhalten der ebenen Gitter ihrer Beschaufelung. Dissertation, University of Hanover, 1977.

7 Shcheglyaev, A. V. Steam Turbines (in Russian), 1976 (Energia, Moscow).

8 Saul, A.-H. Eine Fundamentalgleichung für den fluiden Zustandsbereich von Wasser bis zu Drücken von $25000 \mathrm{MPa}$ und Temperaturen von $1273 \mathrm{~K}$. In VDI Fortschrittsberichte, Vol. 3, no. 149, 1988 (VDI Verlag).

9 Schmidt, D., Riess, W., et al. Flow studies on CHPP turbines in heating and low-load operation. VGB Kraftwerkstechnik, 1995, 75(9) (also German issue).

10 Zehner, P. Calculation of four-quadrant characteristics of turbines. ASME paper 80-GT-2, 1980. 